\title{
Percutaneous closure of ventricular septal defects in childhood
}

Authors: S.C. Brown, A.D. Bruwer and F.E. Smit

SC Brown (principal specialist/ senior lecturer)

AD Bruwer (principal specialist/ senior lecturer)

Division of Paediatric Cardiology, Paediatrics \& Child Health,

Faculty of Health Sciences, University of the Free State, Bloemfontein

FE Smit (principal specialist/ senior lecturer)

Department of Cardiothoracic Surgery, Faculty of Health Sciences,

University of the Free State, Bloemfontein

Corresponding author

Prof SC Brown

Department of Paediatric Cardiology-G 69

Faculty of Health Sciences

University of the Free State

PO Box 339, Bloemfontein, 9300

Email: gnpdscb.md@mail.vovs.ac.za

\section{ABSTRACT Ventricular septal defect is the most common} congenital cardiac lesion. Surgery was, until recently, the only modality of treatment available. Since the first percutaneous closure was attempted, new devices have been developed and used to close these defects. The procedure is safe and effective if the defects are selected correctly with closure being achieved in more than $90 \%$ of patients. Morbidity and mortality are acceptable and comparable to surgery. However, percutaneous ventricular septal defect closure is difficult, technically challenging and should only be attempted in units with adequate experience, equipment and support.

\section{INTRODUCTION}

Ventricular septal defects (VSD) are the most common congenital cardiac defects and account for up to $30 \%$ of all congenital cardiac lesions. (1) Postinfarction VSDs and trauma are responsible for the acquired forms of the defect.

Haemodynamic effects are related to the size of the left to right shunt and vary according to the size of the defect, from negligible to cardiac failure and pulmonary hypertension. Some smaller defects have a high likelihood of spontaneous closure, whilst larger defects persist through adulthood. Long-term complications ofVSDs include infective endocarditis, prolapse of aortic cusps with regurgitation, arrhythmias and pulmonary hypertension, which may lead to Eisenmenger syndrome.
Surgery is regarded as the golden standard in the management of large VSDs. However, percutaneous intervention has progressed markedly over the past decade and opened up new avenues of closure for certain VSDs.

Since Lock used the Rashkind double-umbrella device in 1988 to close muscular VSDs, numerous other devices such as coils, Button device, Cardioseal and other have been used. (2) Currently, the Amplatzer muscular and perimembranous VSD devices are the only occluders specifically designed for VSD closure and are probably the most universal devices implanted for this purpose.

\section{ANATOMY OF A VSD}

Different types of "simple" VSDs have been described according to their anatomical location. By far the most common are perimembranous VSD (70-80\%), muscular VSD (5-10\%) and inlet VSD (5- I0\%). VSD is also an element of atrioventricular septal or atrioventricular canal defects (AVSD) as well as more complex lesions, but these fall outside the scope of this discussion.

Anderson uses the anatomical relationships as viewed from the right ventricle as the primary criterion to describe the defect ${ }^{(3)}$ (see Figure I). TheVSDs can thus be placed in three groups:

I. Perimembranous defects - lie adjacent to the area of continuity between atrioventricular and arterial valves.

2. Muscular defects - usually enclosed within the muscular interventricular septum and can be between inlet, outlet or apical areas.

3. Doubly committed defects - these are directly related to the aortic and pulmonary valves.

It is important to recognise the fact that the membranous septum is directly confluent with the area of fibrous continuity between the aortic and mitral valve (as viewed from the left ventricle). It is also related to the fibrous tissue that occupies the space between the non-coronary and right coronary cusps of the aortic valve. On the right ventricular aspect, the membranous septum is crossed by the hinge point of the septal leaflet of the tricuspid valve that divides it into atrioventricular and interventricular components. This is an important anatomical landmark, since the conduction tissue penetrates this septum from the triangle of Koch and then runs in the crest of the membranous septum, sandwiched between fibrous and muscular septal components.

A defect in the membranous septum should always have the fibrous continuity between aortic and tricuspid valves at its posteroinferior margin. 


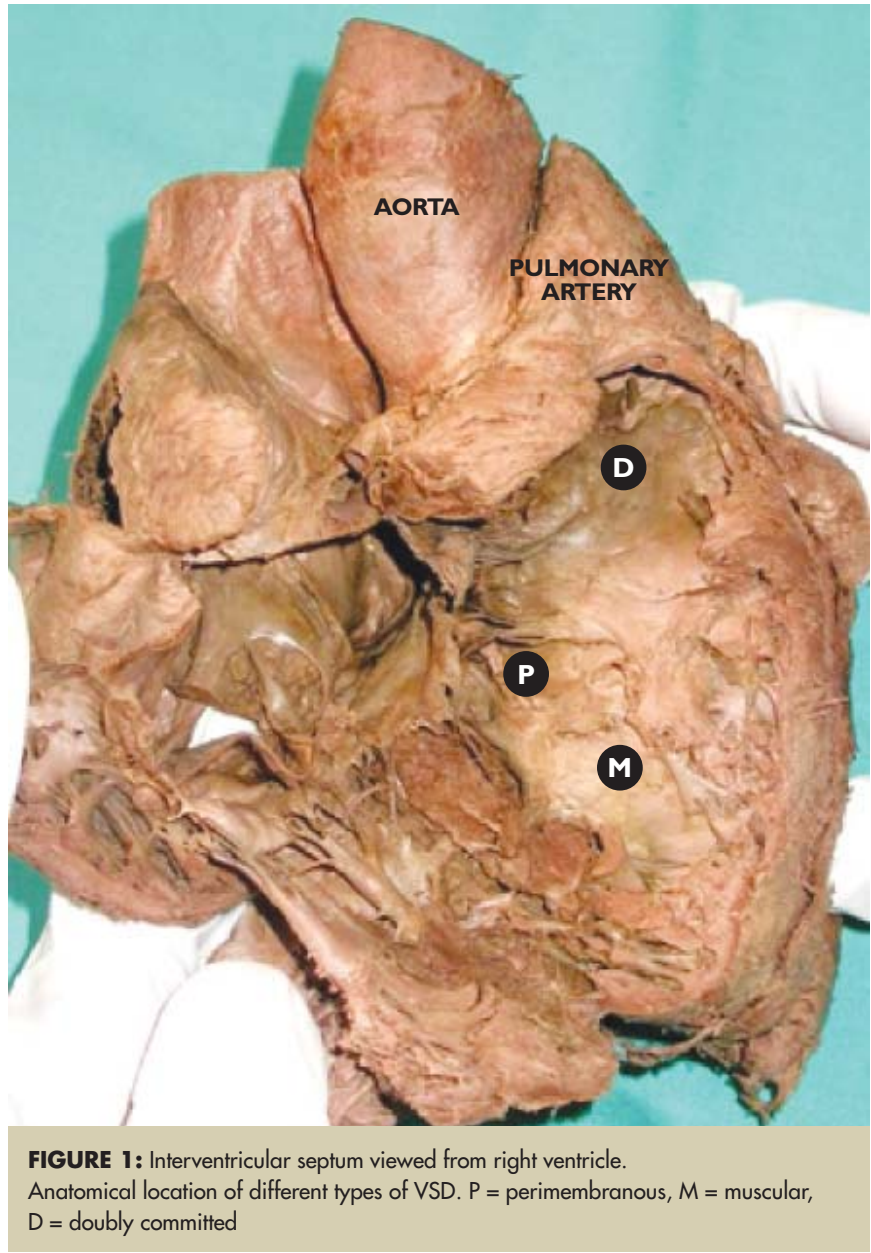

This continuity is an important feature of perimembranous defects. Defects should also be described according to their relationships relative to the components of the right ventricle, as well as to the valvar components (overriding). Perimembranous defects usually extend into the inlet section of the right ventricle, but may also extend into the outlet portion of the ventricle or may be confluent, i.e. extending into both inlet and outlet components. When a perimembranous defect extends to communicate mostly with the right ventricular inlet, the anterosuperior margin is formed by the aortic valve and posteroinferior part by a conjoined area of mitral to tricuspid continuity. If a perimembranous defect extends into the outlet portions of the ventricle, the medial papillary muscle is related to the posterioinferior rim and the outlet septum may be separately recognised.

Muscular defects may be single or multiple or coexist with other defects. An important recognisable feature is the fact that a bar of muscle always interposes between the mitral and tricuspid valve hinge points.

Echocardiographic evaluation of the defects is very important when percutaneous closure is considered. General features during transthoracic echocardiography are presented in Figures 2 and 3.

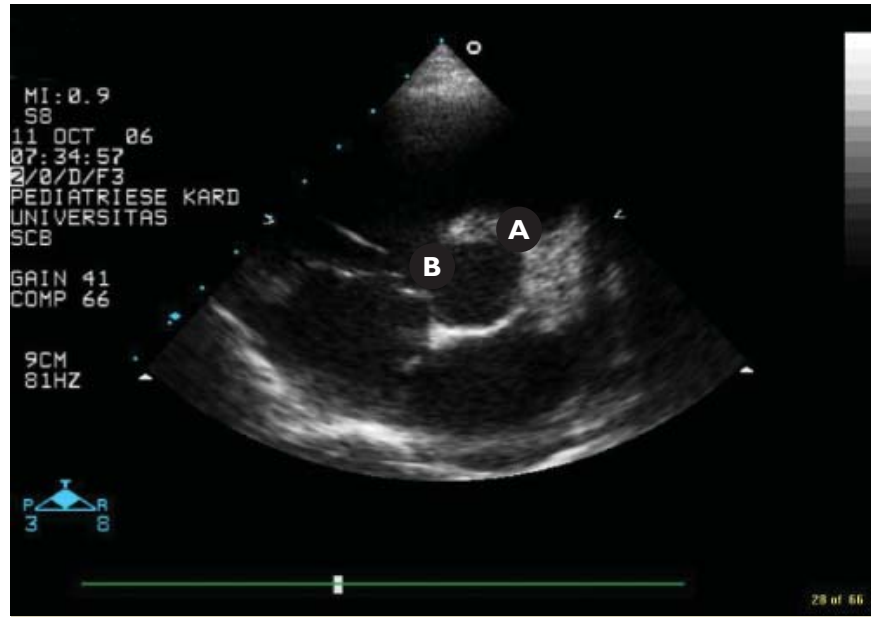

FIGURE 2: Short axis Echocardiogram.

$A=$ perimembranous VSD, $B=$ position of doubly committed VSD

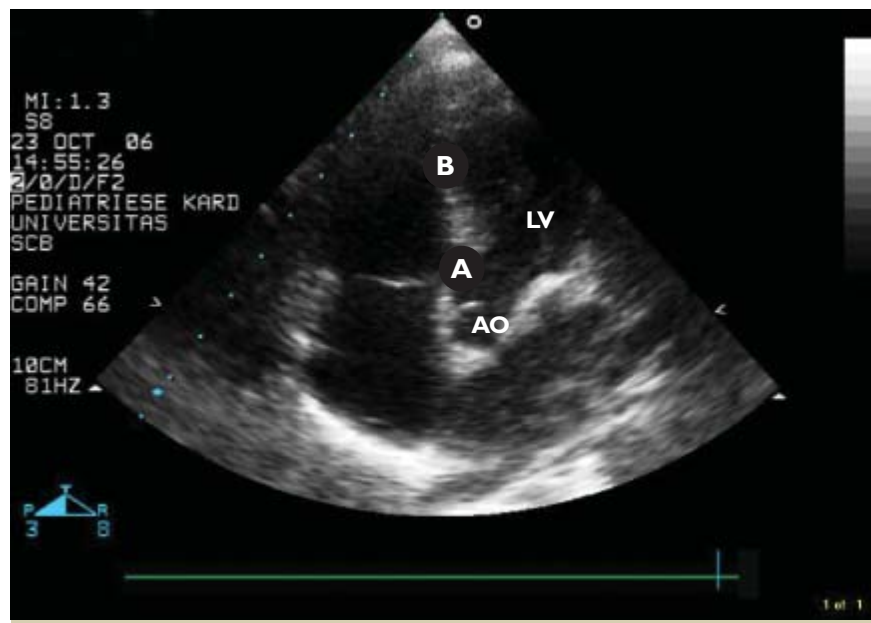

FIGURE 3: Five Chamber Echocardiographic view.

$A=$ perimembranous $V S D, B=$ position of muscular VSD

\section{VSD CLOSURE}

\section{Indications for closure}

General indications for closure in unrestrictive VSD include symptomatic VSD and reversible pulmonary hypertension (pulmonary resistance $<7$ Woods Units). (1-3) The indications for closure in restrictive VSD are not as clear.Mosttextbooks recommend closure if the pulmonary to systemic shunt is (3) $2: 1$ in patients without the presence of pulmonary hypertension, whilst more recent articles suggest a shunt size of $>1,5: 1$ as an indication for closure. ${ }^{(4)}$ VSD-relatedcomplicationssuchasendocarditisorthedevelopment ofaortic regurgitation is also regardedas indication forclosure. Device closure should not be attempted in the following: infants $<8 \mathrm{~kg}$, distance less than $4 \mathrm{~mm}$ between VSD and valvar structures, pulmonary resistance more than 7 Woods units or contra-indications to treatment with salisylates. ${ }^{(5)}$

\section{AmplatzerVSD devices}

The Amplatzer group of VSD devices (AGA Medical Corporation) are made of a nickel and Titanium alloy, Nitinol, which consists of 55\% nickel 
PERCUTANEOUS

CLOSURE OF

VENTRICULAR SEPTAL

DEFECTS IN CHILDHOOD

and $45 \%$ titanium. It is essentially a self-expandable wire mesh, comprising a central connecting waist and two flat discs with polyester fabric covering the inside (see Figures 4 \& 5).

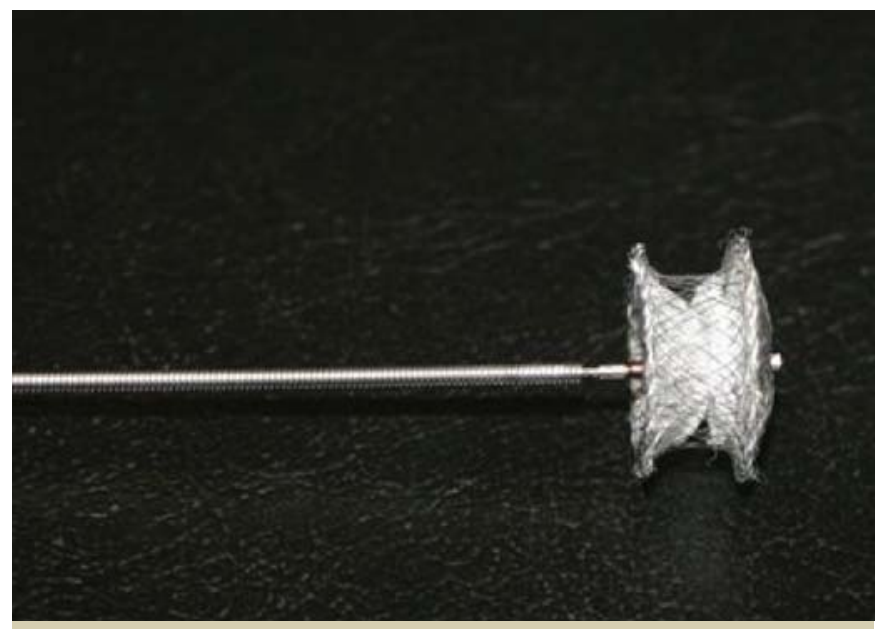

FIGURE 4: Amplatzer muscular VSD device attached to delivery cable.

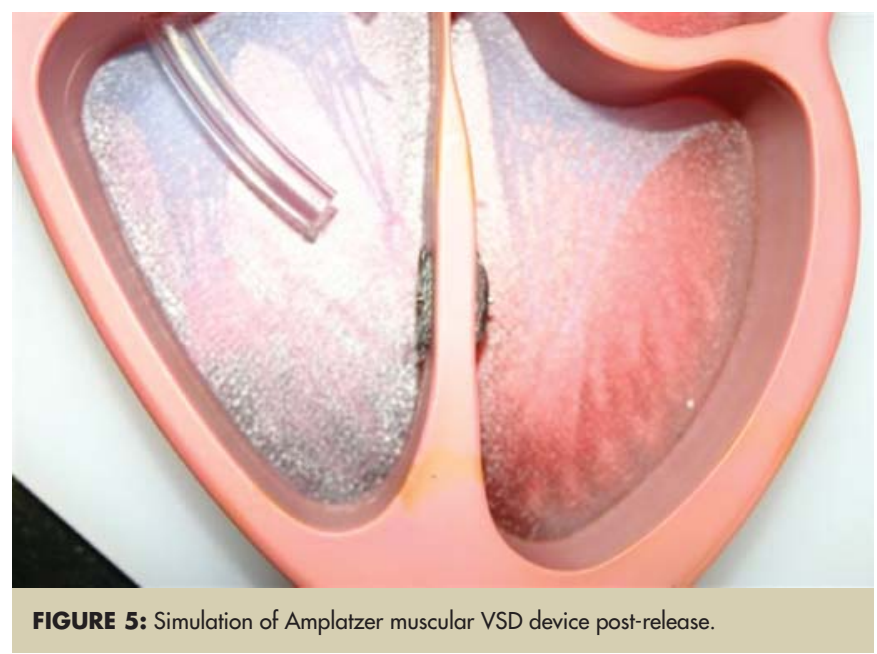

Three devices for the different defects are available: muscular, membranous and post-infarct VSD devices. The membranous VSD occluder has an asymmetrical left ventricular disc with a shorter aortic component to avoid impingement of the aortic valve, whilst the post-infarct device has a longer waist and discs to accommodate the thicker adult interventricular septum. The muscular and membranous VSD devices are available in sizes ranging from $4-18 \mathrm{~mm}$ and the post infarct device from $16-24 \mathrm{~mm}$. Delivery sheath size for muscular and membranous devices range from 6 - 9 French.

\section{Technique}

Compared to patent ductus and atrial septal defect closure, VSD closure is considerably more complicated. It is thus important to recognise that this procedure should only be undertaken in units with sufficient skill, knowledge, adequate equipment and surgical backup.

Complete details of the procedure have been described, ${ }^{(2,6)}$ but a brief summary follows. Some variations of the technique occur, dependent on the type and location of the VSD.
The procedure should be performed under general anaesthesia, and continuous transoesofageal echocardiography (TEE) is a crucial and integral element of percutaneous VSD closure. A complete routine catheterisation and angiographic evaluation should be carried out, as well as a thorough echocardiographic assessment. Sufficient time should be spent to obtain multiple views at different angles of the VSD, as well as evaluation for valvular regurgitation and function.

Access is usually gained via the femoral artery and vein, although the right internal jugular vein may be used for certain muscular VSDs. Activated clotting time is maintained above 200 seconds throughout the procedure.

The device selected is usually I $-2 \mathrm{~mm}$ larger than the maximal diameter of the defect as assessed by TEE and angiography, although there is a move not to exceed the maximum diameter of the defect by much. Balloon sizing is hardly ever used, since the interventricular septum is regarded to be a non-stretchable structure.

Normally, the VSD is crossed from the left ventricle using a right coronary artery catheter. An exchange guidewire is then placed into the left or right pulmonary artery. This guidewire is subsequently snared and exteriorised via the femoral vein. The delivery sheath is then advanced via the right femoral vein and right ventricle into the aorta. Care should be taken to avoid undue tension on the arteriovenous loop and the VSD, as this may cause rhythm disturbances and/ or kinking of the sheath. A "kissing" catheter technique is used when the VSD is crossed by the sheath to avoid direct contact of the guidewire with the VSD. After removal of the dilator, the delivery sheath is then gently withdrawn to a safe position in the left ventricle.TEE guidance is absolutely vital throughout the procedure.

The proper sized device is then screwed onto the delivery cable and advanced to the tip of the long sheath. Special care should be taken to avoid the occurrence of air embolism. The left ventricle disc is then employed within the cavity of the left ventricle and gently pulled to the interventricular septum. This is done under continuous TEE and intermittent angiographic guidance. The waist portion is then deployed, and when in proper position, the right ventricular disc. Before release, careful attention should be paid to proper positioning of the device. It is also important to establish that there is no impingent of valves or other structures. During this period the device can still be recaptured into the sheath and repositioned. The membranous device has a platinum marker in the left ventricular disc, which when properly aligned, should be facing the patient's feet. Once proper positioning has been achieved, the device may be released by unscrewing it counter clockwise using the pin vice. After release, confirmation of correct positioning should be established using TEE and angiography.

Typically 3 doses of an antibiotic are given and the patient observed for 24 hours. ECG monitoring should be done during this period. Endocarditis prophylaxis is recommended for 6 months and the patient should receive a low dose of an anti-platelet agent or aspirin. 


\section{Other techniques of implantation}

The device may also be implanted during surgery as an element of the so-called hybrid procedures. This may be accomplished with or without cardiopulmonary bypass. Usually the device is implanted by direct perforation of the right ventricle underTEE or epicardial echocardiographic guidance.

\section{RESULTS OF PERCUTANEOUS CLOSURE}

\section{MuscularVSDs}

Results largely depend on the type of device used and thus vary widely. Successful implantation is usually possible in most patients - 95\% according to the preliminary European report. (7) Some devices had residual shunts ranging from $25-60 \%$. As with the ASD devices, early residual leaks are common and success is best assessed looking at closure after 12 months. Amplatzer muscular occluders were reported to have occlusion rates of up to $93 \%$ after 12 months. ${ }^{(8-12)}$ Residual shunting that remained was mostly classified as trivial. Residual shunting of varying degrees is also common after surgery, occurring in up to $53 \%$ of cases. ${ }^{(4)}$

\section{Perimembranous VSDs}

The Amplatzer membranous device is the only device specifically designed for this lesion. These lesions are technically particularly challenging. Satisfactory device impantation is possible in up to $97 \%$ of patients with a one-year complete closure of between $90-100 \%$ in reported series ${ }^{(5)}$, (12-17) depending on the complexity of the lesion. Recently, muscular VSD occluders were used with success to occlude perimembranous VSDs in patients with significant aneurysm formation present. ${ }^{(18)}$

Concerns have been raised whether this is an acceptable alternative to surgery, as the complication rate in some studies has been unacceptably high, particularly with regard to the development of heart block. (12 14 16)

\section{COMPLICATIONS}

\section{Haemolysis}

This complication is usually associated with residual shunt after attempted device closure and may occur in $0.8 \%$ of cases. ${ }^{(15)}$ In some instances it may be severe and transient renal failure ${ }^{(19)}$ and needs for blood transfusion have been described. It has been suggested that it may be minimized by soaking the device in the patient's own blood pre-implantation.

\section{Air embolism}

This is an avoidable complication and can easily be avoided by paying meticulous attention to technique during catheter and wire exchanges.

\section{Device embolisation}

Both systemic and right heart embolisation of the device may occur and has been reported in up to $2 \%$ of cases. It seems to be related to operator experience, and highlights the importance of continuous TEE monitoring during the procedure. Operators should be familiar with retrieval techniques and all necessary equipment for retrieval should be available. Surgical backup is also considered essential.

\section{Valvular regurgitation}

The device may influence function of any of the valves, but especially with the membranous device, aortic and tricuspid regurgitation should actively be looked for with TEE prior to release of the device. It seems that if a minimum distance of $4 \mathrm{~mm}$ from the aortic valve is observed, aortic regurgitation usually does not occur. Significant aortic regurgitation developed in up to $15 \%$ in one series. ${ }^{(5)}$ Mild aortic regurgitation was more common, but some of the regurgitation was transient and improved after six months.

\section{Cardiac perforation}

Complications of this nature are usually related to catheter and/or guide wire perforation of the cardiac chambers. This may lead to pericardial effusion, but neither tamponade nor delayed effusion related to the device has been described to date.

\section{Dysrhythmias}

During catheter and device manipulation temporary dysrhythmias, usually ventricular, are common. Right bundle branch block occurred in only $6 \%$ of patients ${ }^{(5)}$ compared to up to $64 \%$ of reported surgical series $^{(4,20)}$. Completeheartblockmayalso comeabout during the procedure, but cases of delayed development of complete block have been described. Most respond to treatment with steroids and anti-inflammatory agents ${ }^{(21)}$, but permanent pacemaker implantation has also been necessary - the latter especially in cases of delayed atrioventricular block. ${ }^{(12)}$ It is therefore imperative to have an experienced anaesthetist in theatre during the procedure. Knowledgeable personnel should also regularly follow up these children. Complete heart block most often follows implantation of the membranous VSD device. The exact cause is not known, but local trauma with haematoma due to manipulation of catheters and guide wires during catheterisation and inflammatory response to the device or mechanical compression due to continued expansion of the device may be responsible for complete block, which occurs in up to $3.5 \%$ of procedures. This compares favourably to surgery, where complete heart block may occur in up to $3.1 \%$ of children. ${ }^{(4)}$

\section{Other}

Although rare, serious complications, such as death, have occurred in $2-3 \%$ of patients. In surgical procedures, death was reported in $0-4,3 \%$ of cases after 1980. (4) Recently, the first case of endocarditis developing postimplantation, which was successfully treated with conservative measures, was reported. (22)

\section{POST-INFARCTION VSD}

Post-infarctionVSD is a serious complication and without treatment mortality may be more than $90 \%$. Even with surgical closure, mortality varies from 19 - 46\%. Closure using percutaneous devices has had promising results, although frequently associated with residual shunts. Mortality was comparable to surgery $(<28 \%)$. Transcatheter closure of recurrent post-infarction VSD following patch repair is currently probably the treatment of choice. ${ }^{(23-25)}$

\section{CONCLUSION}

Transcatheter management of ventricular septal defect is now feasible for a wide variety of muscular and perimembranous VSDs. The AmplatzerVSD devices are specifically designed forVSD occlusion and seem effective and safe. Other devices, designed for other lesions, should only be considered in individual cases. Percutaneous closure should only be attempted on properly selected patients in units with sufficient experience and suitable echocardiographic equipment, together with surgical backup. The closure of perimembranous defects is not as yet routinely done. 
PERCUTANEOUS

CLOSURE OF

VENTRICULAR SEPTAL

DEFECTS IN CHILDHOOD

\section{Commentary: a surgical perspective}

Author: F.E. Smit

Surgical VSD closure remains the golden standard for routine VSD closure with a mortality rate of $0-2.3 \%$. ${ }^{(26)}$ However, the significant progress in the development of percutaneous devices cannot be ignored and in certain specific settings, like muscularVSDs and post-infarctionVSDs, provide for an acceptable and attractive alternative treatment. This might be approached as an independent percutaneous intervention or in a hybrid fashion (with or without cardiopulmonary bypass).

Peri-operative mortality in the post-infarction VSD group still ranges from $16-49 \%$ and percutaneous closure in these extremely ill patients might become the treatment of choice for isolated post-infarction VSD in future.

The perimembranous group, which constitutes $70 \%$ of VSDs, still raises concerns. As mentioned above, a $4 \mathrm{~mm}$ muscular rim is required, the device can impact on (especially) aorta valve function, it cannot be used in children of less than $8 \mathrm{~kg}$ in weight and it causes heart block in up to 3.2\%. Heart block incidence afterVSD closure is $<1 \%$. (27)

The incidence of haemolysis and residual VSD (93\% closure at one year), remains of concern, as well as device embolisation.

The published series of device closures mostly refers to older children with weights in excess of 8 kilograms (restrictive VSDs), but exclude small, growth compromised children with large VSDs, the "bread and butter" referral for surgery. It will be an erroneous belief to postpone surgical closure in this group in favour of later device closure.

This is an exciting and potentially very useful development, which we as surgeons should approach with an open, though evidence based, mind. 


\section{REFERENCES:}

I. McDaniel NL, Gutgesell HP. Ventricular Septal Defects. In: Allen HD, Gutgesell HP, Clark EB, Driscoll DJ. Moss and Adams' Heart Disease in infants, children and adolescents, Sixth Edition. Baltimore: Lippincott Williams \& Wilkins; 2001: 636-5I.

2. Holzer R, Hijazi ZM. An overview of device closure of ventricular septal defects using the Amplatzer devices. Medical and Surgical Pediatrics 2005;27: S33-S44.

3. Tynan M, Anderson RH.Ventricular septal defect. In: Anderson RH, Baker EJ, Macartney FJ, Rigby ML, Shinebourne EA, Tynan M. Paediatric Cardiology, Second Edition. London: Churchill Livingstone; 2002:983-1014.

4. Nygen A, Sunnegardh J, Berggren $H$. Preoperative evaluation and surgery in isolated ventricular septal defects: a 21 -year perspective. Heart 2000;83:198-204.

5. Fu Y, Bass J, Amin Z et al. Transcatheter closure of perimembranous ventricular septal defects using the new Amplatzer membranous VSD occluder. JACC 2006;47:31 9-25.

6. Hijazi ZM. Device closure of ventricular septal defects. Catheter Cardiovasc Interven 2003:60:107-114

7. Carminati M. Transcatheter treatment of congenital and postinfarction ventricular septal defects: preliminary results of an European multicenter study. Medical and Surgical Pediatrics 2005;27: S47-49.

8. Djer MM, Latiff HA, Alwi M, Samion H, Kandavello G. Transcatheter closure of muscular ventricular septal defect using the Amplatzer devices. Heart Lung and Circulation 2006;1 15:12-17

9. Thanopoulos BD. Catheter closure of congenital muscular ventricular septal defects. Pediatr Cardiol 2005;26: 1004-6.

10. Carminati M, Butera G, Chessa M, Drago M, Negura D, Piazza L. Transcatheter closure of congenital ventricular septal defect with Amplatzer septal occluders. Am J Cardiol 2005;96:52L-58L

II. Holzer R, Balzer D, Cao Q, Lock K, Hijazi ZM. Device closure of muscular ventricular septal defects using the Amplatzer muscular ventricular septal defect occluder. JACC 2004;43: 1257-63

12. Masura J, Gao W, Gavora P et al. Percutaneous closure of perimembranous ventricular septal defects with the eccentric Amplatzer device: Multicenter follow-up study. Pediatr Cardiol 2005:26:216-219.

13. Pedra CA, Pedra SR, Esteves CA et al. Percutaneous closure of perimembranous ventricular septal defects with the Amplatzer device: technical and morphological considerations. Catheter Cardiovasc Interven 2004:61:403-10.

14. Holzer R, de Giovanni J, Walsh KP et al. Transcatheter closure of perimembranous ventricular septal defects using the amplatzer membranous VSD occluder: immediate and midterm results of an international registry. Catheter Cardiovasc Interv 2006;68:620-8.

15. Zha YS ,Li H, Liu JP et al. Complications of transcatheter interventional occlusion of ventricular septal defects. Zhongua Er 2005;43:35-8.

16. Kalra GS,Verma PK, Dhall A, Singh S, Arora R. Transcathater device closure of ventricular septal defects: immediate results and intermediate term follow-up. Am Heart J 1999; | 38:339-44

17. Michel-Benke I,Trong L, Waldecker B, Akintuerk H, Valeske K, Schranz D. Percutaneous closure of congenital and acquired ventricular septal defects - considerations on selection of occlusion device. J Interventional Cardiol 2005; 1 8:89-99.

18. Szkutnik M, Quereshi SA, Kusa J. Rosenthal E, Bialowski J. Use of the Amplatzer muscular ventricular septal defect occluder for closure of perimembranous VSDs. Heart Online First, Sept 15, 2006 10.1 136/hrt2006.

19. Spence MS,Thomson JD,Weber N, Quereshi SA. Transient renal failure due to hemolysis following transcatheter closure of a muscular VSD using an Amplatzer muscular VSD occluder. Catheter Cardiovasc Interven 2006;67:663-67.

20. Yaeger SB, Freed MD, Keane JF, Norwood WI, Castaneda AR. Primary surgical closure of ventricular septal defect in the first year of life: results in 128 infants. ACC 1984:3:1269-76

21. Yip WCL, Zimmerman F, Hijazi ZM. Heart block and empirical therapy after transcatheter closure of perimembranous ventricular septal defect. Catheter Cardiovasc Interven 2005:66:436-4I.

22. Scheuerman O, Bruckheimer E, Marcus N, Hoffer V, Garty B. Endocarditis after closure of ventricular septal defect by transcatheter device. Pediatrics 2006; I 17:1 256-58.

23. Walsh KP.Transcatheter closure of post-myocardial infarction ventricular septal defects. Medical and Surgical Pediatrics 2005;27: S44-46.

24. Holzer R, Balzer D, Amin Z et al. Transcatheter closure of postinfarction ventricular septal defects using the new Amplatzer muscular VSD occluder. Catheter Cardiovasc Interven 2004;61:196-201.

25. Garay F, Cao QL, Hijazi ZM. Percutaneous closure of postmyocardial infarcation ventricular septal defect. J Interv Cardiol 2006; 19:S67-72.

26. Castaneda A R, Jonas RA, et al. Cardiac Surgery of the Neonate and Infant. Philadelphia, WB Saunders; 1994: 198

27. Anderson, $\mathrm{H}$ O, Tsang VT,et al. Is Complete heart Block after Surgical Closure of Ventricular Septal Defect Still an Issue. Ann. OfThor Surg, 2006;82:948 -956 